\title{
Relations with the Educational Community and Transformative Beliefs against Gender- based Violence as Preventive Factors of Sexual Violence in Secondary Education
}

\begin{abstract}
Nowadays sexual violence among adolescents continue to be detected in schools. In this sense, several studies show the great importance of the interactions of boys and girls with people in their educational environment to configure their emotional and sexual identity, their beliefs about violence, and their relationship with sexual violence, being necessary to identify the actions that prevent sexual violence at schools. In the current paper, and according to literature review, a model based on structural equations is proposed to analyze the influence of students' relationships with one another, with the educational community (at the center, with faculty, staff, other workers) and families' relationships with the center as well as adolescents' own beliefs related to gender violence on being a victim, bystander or aggressor of behaviors related to sexual violence in a sample of 4,273 Spanish students in secondary education. This model is replicated for only women $(n=2,022)$ and only men $(n=2,038)$. The results show that positive relationships are a protective factor against involvement in situations of sexual aggression, and they influence the acquisition of transformative beliefs regarding models of attraction and nonviolence. In turn, these beliefs even more obviously affect the prevention of this type of violence.
\end{abstract}

Keywords: violence, school context, prevention, socialization, sexual violence

\section{Introduction}

In the last decade, the growing concern about sexual and gender violence among adolescents has promoted greater attention by the international scientific community on the factors that influence its causality (Fernet, Hébert, Couture \& Brodeur, 2019)). In this sense, several studies show the great importance of the interactions of boys and girls with people in their environment 
(peers, relatives, educational staff, etc.) to configure the emotional and sexual identity of adolescents, their beliefs about violence, and its relationship with sexual violence (Valls, et al., 2008; San Segundo \& Codina-Canet, 2019; Puigvert, et al., 2019; L'Engle \& Jackson, 2008). Thereby, the strategies for the primary prevention of this problem (prevention before any attempt at aggression, Villarejo-Carballido, et al. 2019) have begun to focus on the analysis of the exclusionary beliefs towards relationships, such as an attraction to aggressive boys or relationships based on control and domination (Gómez, 2015), that can be disseminated through the interactions that students maintain with their peer group (Flecha, et al., 2017).

Thus, the present article explores the importance of the interactions that adolescents maintain with their educational environment to the conformation of affective sexual beliefs and the relationship of these both variables with sexual violence. To this end, a model based on structural equations is proposed to analyze the influence of students' relationships with one another, with the educational community (at the center, with faculty, staff, other workers) and families' relationships with the center as well as adolescents' own beliefs related to gender violence on being a victim, bystander or aggressor of behaviors related to sexual violence in a sample of 4,273 Spanish students in secondary education. The model is then replicated for the samples of only girls $(n=2,022)$ and only boys $(n=2,038)$.

\section{Sexual Violence among Adolescents: Incidence of the Problem and the Role of Socialization in its Causality}

Although traditionally identified as an adult problem, the increasing media impact of news related to sexual violence among adolescents, and the statistical figures that prove the prevalence of its incidence, have increased the scientific interest in the identification of its causes and, consequently, strategies for its prevention (Fernet, et al. 2019). Thus, according to the Spanish National Institute of Statistics (2019), in 2018 (the last year with published data), 1,833 procedures were recorded for sexual crimes committed by minors in Spain (14-17 years 
old people, being boys the $98 \%$ of them), with an increase of a $69,9 \%$ in four years. Sexual and gender violence is considered to be a public health issue whose awareness extends internationally, as shown by studies such as Eisman et al. (2018) or Kaltiala-Heino, et al. (2018).

According to the World Health Organization (WHO), sexual violence "encompasses acts that range from verbal harassment to forced penetration, and an array of types of coercion, from social pressure and intimidation to physical force" (WHO, 2012, p.1); in addition, "Sexual violence, including sexual harassment, often occurs in institutions assumed to be 'safe', such as schools (...) including classrooms" (2012, p.4). In fact, educational centers have been identified in several Spanish studies as places where episodes of sexual violence occur regularly, either between peers or between adolescent couples (Fernández-Fuertes, et al. 2006; Ortega, et al. 2008).

These investigations characterize the sexual violence that occur among adolescents in educational centers as an extension of other situations of physical and/or relational bullying (Ortega et al., 2008). These works show that this type of violence is more frequent in sporadic couples or groups of equals (more than in "consolidated couples"), and usually, girls are the victims, and boys are the aggressors (Ortega et al., 2008; Díaz-Aguado, et al. 2013), although boys can also appear to be victims if they are perceived as "weak" by their classmates, as Messerschmidt states (2017).

The aforementioned studies and other studies, such as the research conducted by SánchezTeruel \& Peñaherrera-León (2013), attribute the causality of sexual violence in school to the transfer of the social domain-submission scheme, in which some students control and other students are controlled, such as in other situations of bullying, which transfers this scheme to different contexts (from the family to the school, from the school to other areas of socialization, or from adolescence to adulthood, for example). There is, therefore, a risk of becoming a 
structural dynamic, and the attitudes that these young people suffer from or witness in their adolescence are reproduced in their future adult relationships (Gómez, 2015; Eisman et al., 2018).

In this dominion-submission scheme, adolescents' acceptance of it is very important because, on many occasions, the socializing dynamics (especially from the media and among adolescents themselves) encourage the association between attraction and domain or, similarly, between attraction and violence (Valls, et al., 2008; Elboj, et al., 2009). In these and other works (Gómez, 2015; Rios-González, et al. 2018), the close relationship between the messages that are transmitted in the different interactions with other agents of socialization and the assumption of exclusionary beliefs can lead to situations of sexual violence, either as an aggressor, as a victim, and although less explored by the literature, as a bystander.

\section{Protective Interactions and Beliefs as Elements of the Prevention of Sexual Violence}

\section{among Adolescents: A Hypothetical Model}

In relation to the discussion above and according to Gómez (2015) and Rios-González et al. (2018), the eradication of possible sexual violence among adolescents requires preventive actions that begin in the schools of secondary education or, even before secondary education. by analyzing the interaction processes that adolescents maintain with their environment and the beliefs that are assumed from these interactions. In this sense, the main objective of this article is to analyze how both the interaction processes and the beliefs assumed from these interactions influence participation as victims, aggressors or bystanders in situations of violence in school. In the absence of previous structural models that have explored these elements, for the hypothetical model that we propose in the present investigation, we base it on previous works that, mostly qualitatively, emphasize the importance of the relationships between adolescents and their environment and the assumed beliefs regarding the association between attraction and violence. 


\section{[Insert Figure 1 here]}

First, to analyze the participation in situations of sexual violence (as dependent variables), the selected variables were "victim of sexual violence", "aggressor of sexual violence" and "bystander of sexual violence", all of them in the educational center. Although, traditionally, the agents who have received more attention from the scientific literature on the subject are the victims and the aggressors (Ngo, et al. 2018; Fernet, et al. 2019; Eisman et al., 2018; Barbara et al., 2017; Foshee et al., 2016), the incorporation in the analysis of the bystander figure is becoming more frequent (Jouriles, et al. 2019; Miller, 2019; Storer, et al. 2017), even in the analysis of the violence between adolescent couples (De La Rue et al., 2014). This phenomenon is because scientific research is demonstrating the importance of this agent when passing from bystander to upstander who helps in combatting and preventing this type of behavior, takes the side of the victim, or on the contrary, supports this type of violence with permissiveness (Jouriles et al., 2019; Miller, 2019; Storer, et al., 2017).

For the exogenous latent variables, we selected variables that refer to the evaluation of the adolescents themselves about their relationships at school, with other agents (classmates, teachers, managerial staff, and other school staff) and the relation between families and the center ("relationships at school"). As verified by the studies of Foster et al. (2017), Hong, Lee, et al. (2014) and Rawlings (2015), the choice of this variable is given for school connectedness as a fundamental protection factor to prevent situations of bullying, given that "bully perpetration and victimization is concurrently and longitudinally associated with low levels of school connectedness and student engagement with his/her close context" (Cortés-Pascual, et al. 2019, p.3). All the previous authors start from Bronbrenbrenner's (1979) ecological model, which explains that the actors involved in aggressions at school (as victims, aggressors or bystanders) can be considered to be the cause of the relationships or the lack of them at the microsystemic (relationships with a group of equals, family, or teachers) (Yang, 2005), 
mesosystemic (relationships that occur between microenvironments) (Harris \& Petrie, 2003), exosystemic (viewers who do not participate directly although they witness violence) (Shin, 2000) and macrosystem (alluding to the culture of individualization, aggression and absolute imposition) levels (Santoyo Castillo \& Frías, 2014).

This dynamic and its importance is also applicable to sexual and/or gender violence, given that the interactions of adolescents are essential in shaping their ideas about violence, love, respect or their idea about their own sexual affective relationships (Racionero, et al., 2018). Authors such as Bakhtin (1981) and Mead (1934) argue that, through dialogue, individuals internalize the different social representations assumed by the agents with whom they interact. Therefore, interactions with the family, a group of friends or other educational agents appear to be especially relevant agents in the creation of the way that adolescents have to interpret relationships (Joanpere \& Morlà, 2019; Valls, et al., 2008; Racionero, et al., 2018). Therefore, these interactions are either a possible risk factor towards gender and/or sexual violence if such influence is negative (L'Engle, et al., 2006;) or a preventive factor if the influence is positive (Gómez, 2015; Valls, et al., 2008; Elboj et al., 2009; Rue, 2014; Shakya, et al., 2019). In this sense, school appears to be an ideal place to work on respect and nonviolence and, in turn, beliefs in relation to these issues and how they are shaped through interactions, as specified by Racionero, et al. (2018). To this end, not only classmates and other educational agents must be considered but also family influence, given that the family's socializing role is fundamental in the conformation of affective-sexual behaviors, as emphasized by Rios- González, et al. (2018); therefore, it is necessary to promote the participation of families in preventive socialization.

Derived from the analysis of adolescents' interactions and their influence on adolescents' understanding of relationships, a variable of mediation between these relationships and the participation in situations of sexual violence has been included in the model: the beliefs 
assumed in relation to control in the couple and the union of attractiveness with violence ("Beliefs related to gender violence"). These beliefs are assumed to be a dependent variable of "relationships at school" (independent variable), given that all authors claim that this directionality is the importance of socialization in the assumption of beliefs related to interpersonal relationships. Specifically, the degree of agreement with the statements "The man who seems aggressive is more attractive" and "It is justified that a man assaults his wife or his girlfriend when she decides to leave him" is measured. A study on the values in education to prevent gender violence in secondary schools concludes that adolescents tend to be attracted to individuals who have favorable attitudes towards the model of hegemonic masculinity that reproduce the values of domination, especially in the case of boys, and submission, especially in the case of girls (Elboj, et al. 2009, Rios-González, et al., 2018). These studies, together with the research by Aiello, et al. (2018), show that violent boys tend to be considered more attractive than the boys who have a more friendly and attentive personality, which is a fact that constitutes a risk factor. Thus, the relationship between the attraction to the hegemonic model of masculinity and violence is one of the possible causes of the high rates of incidence of gender violence in the adolescent population (Goldstein, et al. 2007). In fact, the popularity of the models of sexual and affective attractiveness, which can deviate to aggressive behaviors, is accepted on many occasions by adolescents in their daily environments, which reinforces the image of the aggressor, especially in the case of boys, as Lloyd, et al. (2008) or Mahlstedt \& Welsh (2005) have demonstrated in their studies. Conversely, if these beliefs have a more transformative component that rejects the idea of attraction for violence or the association of domination with love, the possibilities of incurring situations of gender violence or sexual violence decrease significantly (De La Rue et al., 2014; Elboj, et al. 2009; L'Engle \& Jackson, 2008; Racionero, et al., 2018). 


\section{Methods}

\section{Participants}

For the present analysis, information was collected from students in the secondary educational stage (first cycle of Educación Secundaria Obligatoria - from 11 to 15 years old) in 20 schools of the Autonomous Community of Aragon (Spain) considering the stratified representation of the provinces ( 3 in Huesca, 2 in Teruel and 15 in Zaragoza), private and public schools ${ }^{1}$, and rural and urban areas. From here, the selection of the centers was random. A total of 5,028 participants completed the survey, although only the cases that did not present lost values in the analyzed variables on bullying and cyberbullying were selected; finally, a sample of 4,273 students was obtained. Regarding the characteristics of the participants of the survey, the majority were Spanish $(91.0 \%$, with the remaining $9.0 \%$ representing 47 different countries, being the most representative after Spain: Romania 1.0\%, Colombia and Morocco $0.7 \%$ both, and Nicaragua and China $0.6 \%$ both), the distribution by sex was equitable $(49.8 \%$ girls and $50.8 \%$ boys), with an average of age of 14.2 years $(\mathrm{SD}=1.4$ years), and the distribution by courses was also equitable $(23.7 \%$ were in the First course, $26.6 \%$ were in the Second course, $24.9 \%$ were in the Third course, and $22.0 \%$ were in the Fourth course). The majority of the students' families were Spanish $(87.7 \%$ of the parents and $87.0 \%$ of the mothers), and $46.8 \%$ of the fathers and $52.2 \%$ of the mothers had university studies. Overall, $14.8 \%$ of the evaluated sample reported having repeated secondary education at least once. Diversity of the sample was ensured by the broad inclusion criteria (all students of the schools and courses random selected participated in the survey) with the purpose of increasing the generalizability of the findings to general practice.

[Insert Table 1 here] 


\section{Instrument}

In this research, the information extracted from a questionnaire designed by the researchers of the project "Study of coexistence in educational centers of Aragon" was used based on questionnaires used in previous studies at the regional and national levels. Through the intermediation of the Government of Aragon, various educational centers were selected through a sampling by conglomerates in this Autonomous Community. After the selection, an invitation was sent to collaborate in the study, together with the information, schedule and objectives of the research, and then, the authorizations and consents of the students' parents or tutors were collected.

During the months of March and April 2017, the teachers and management team of each school coordinated the students' data collection with the support and supervision of the research team of the project. This data collection was carried out entirely online in classrooms enabled for this during school hours. Each participant received a password to access the questionnaire once, which ensured privacy, anonymity and confidentiality during the entire process.

The questionnaire consisted of several sets of questions, among which we emphasize below the questions used for our analysis based on the validated questionnaire developed by DíazAguado et al. (2011; 2013). This questionnaire has been the most used in Spain to measure violence at school, being the instrument used for the largest study on violence at school at state level (2011), and being validated also in our study at regional level. Moreover, the selection of this instrument has been also determined by its inclusion of scales that measure the three constructs that we wanted to explore: students' relationships; students' degree of agreement on beliefs related to violence; and situations of sexual violence at school suffered, perpetrated or witnessed by the students. 
1) Sociodemographic questionnaire with questions concerning sex, age, course, nationality of the students and their parents, father and mother's educational level, or if the participant had repeated courses in primary or secondary education.

2) Questionnaire about the evaluation of the students' relationships with the rest of the educational staff (with their peers in the center, with the faculty, with the management team, and with other staff at the school) and of the students' family's relationships with the center by using a Likert scale between 1 (not satisfied) and 4 (very satisfied). The Cronbach's alpha coefficient for the scale of relationships is .71.

3) Questionnaire about the students' degree of agreement on beliefs related to violence, among which we have selected the two questions that are related to gender violence: "The man who seems aggressive is more attractive" and "It is justified that a man assaults his wife or his girlfriend when she decides to leave him". These questions were evaluated with a Likert scale from 1 (no agreement) to 4 (very much in agreement). In this case, the Cronbach's alpha coefficient is .86.

4) Bullying Questionnaire to measure the bullying suffered (victims), perpetrated (aggressors) and witnessed (bystanders) by the students was implemented that utilized the same scale used by Díaz-Aguado et al. (2013). This instrument raises several harassment situations and their frequency and consists of 19 items answered on a Likert scale that ranges from 1 (never) to 4 (many times). For the present research, the two items have been used, within the scale of bullying, to refer to the violence of sexual content included in the questionnaire: "Intimidate with phrases or insults of a sexual nature" and "Obligate with threats of behaviors or situations of a sexual nature in which he does not want to participate ". These two variables compose the construct of "sexual violence" for victims (suffered), bystanders (witnessed) and aggressors (perpetrated). The Cronbach's alpha for the bullying subscale is .90 in the case of victims, .92 in the case of bystanders and .94 in the case of aggressors. 
Although sexual violence between and towards children and adolescents can occur in different contexts and with different agents involved, in this large study we have focused on the incidents that can happen in schools because, literature has determined, sexual violence often occurs in safe institutions, . Concretely, in Spain, schools and classrooms have been identified as places where episodes of sexual violence occur regularly (Fernández-Fuertes, Fuertes \& Pulido, 2006; Ortega, Ortega-Rivera \& Sánchez, 2008).

\section{Analysis}

First, we performed a descriptive analysis of the variables related to the relationships in the center, the beliefs related to gender violence, and the incidence of sexual violence in secondary education. Accordingly, we considered the three agents that can be part of these aggressions, either directly (victim and aggressor) or indirectly (bystander) by sex by applying the chisquared test to detect possible significant differences between boys and girls.

However, the fundamental objective of our work was to test the influence of positive relationships with the rest of the educational community and the beliefs of adolescents in the prevention of these aggressions. To this end, an analysis that used structural equations (SEM) was implemented through IBM-SPSS-AMOS (v.22) as applied to the hypothesized model derived from the literature for the entire sample (see Figure 1). Thus, the proposed structural model was tested, including the observed variables and latent variables for the entire sample and was replicated for only girls and only boys (see the results section, Figure 2), with the objective of analyzing if there were differences by sex. This model of complete structural equations is used to test the hypothetical patterns of causal structures that relate several variables to the constructed model (Byrne, 2010). The latent and observed variables used in the model are detailed in Table $2^{2}$.

[Insert Table 2 here] 
The estimator selected was the maximum likelihood (MLE), a standard practice to find the values of the parameters that make the observed data more likely. This procedure has also been recommended in the literature on SEM within AMOS (Pérez, Medrano and Sánchez Rosas, 2013, Byrne, 2010). To report the results, we included nonstandardized and standardized regression weights. Although the literature recommends the use of standardized coefficients, to facilitate the interpretation and comparison of the results, the nonstandardized regression weights within the AMOS results provided additional information about the standard errors, the critical residues and the importance of each variable. Finally, the goodness of fit of our model was tested by using RMSEA, CFI, TLI, NFI and GFI as indicators, as recommended by Schlermelleh-Engel et al. (2003), Vandenberg (2006) and Byrne (2010)3.

Finally, this analysis technique was chosen because of the advantages that it has over other more traditional techniques (such as multiple linear regressions, for example). According to Byrne (2010), the SEM application allows the use of multiple dependent variables in the same model, and it is possible to construct latent variables that are more reliable than the observed variables due to the inclusion of measurement errors. Moreover, the analysis produces multiple measures of goodness of fit, which indicate if our model fits the data; therefore, it allows a more reliable interpretation than traditional indicators.

\section{Results}

First, by descriptively analyzing the variables used in the sample, it is observed that in all the variables of sexual violence, the percentage of boys is more significant than the percentage of girls (victimization, observation and aggression), especially in the act of attacking, namely, "Forcing him/her with threats of behaviors or situations of a sexual nature in which he/she does not want to participate" where $6.3 \%$ of the boys do this at least "sometimes". In relation to beliefs, $5.9 \%$ of the total sample is quite or very agreed that "Men who look aggressive are 
more attractive", which does not show significant differences between boys and girls. However, in the statement "It is justified that a man attacks his wife or his girlfriend when she decides to leave him", the percentage of boys who quite or very agreed is double the percentage of girls $(4.7 \%)$. Regarding the evaluation that students make of their relationships at the educational center, in general, they are very positive in all cases, which emphasizes the relationships with their peers $(91.3 \%)$ and between families and the school $(89.0 \%$ are quite or very satisfied). Concerning the differences by sex, the girls seem to be more satisfied than the boys with their relationships with the teaching staff and managerial staff and their families' relationship with the center, although the boys have a higher level of satisfaction in the case of their relationships with peers.

\section{[Insert Table 3 here]}

Moreover, to contextualize the results, about psychological or relational bullying, our survey data showed that $9.7 \%$ of the sample claimed to have been a victim of this type of aggression in recent months at least "sometimes", $15.1 \%$ had been bystanders, and 7.0\% claimed to have been at some point the aggressor using this type of behavior.

Regarding the results of the model for the total sample $(n=4,060)$, all the estimates for the route of the structural parameter were significant $(\mathrm{p}<.05, \mathrm{p}<.01, \mathrm{p}<.001$, critical residues, Est./SE $>1.96)$. The coefficients were negative in the influence of the relationships in terms of becoming a victim $(-.064 * * *)$, bystander $\left(-.053^{* *}\right)$ and aggressor $(-.067 * *)$, which shows that the positive interactions of the students with classmates and the educational staff of the center and their families' positive relationship with the school were protective factors against this type of violence. The influence of these relationships on having beliefs associated with gender violence ("The man who seems aggressive is more attractive" and "It is justified that a man attacks his wife or his girlfriend when she decides to leave him") is even more relevant, and in the same way, negative $\left(-101^{* * *}\right)$; therefore, these positive interactions are also effective in discarding ideas that associate love with violence. In measuring each type of relationship at the 
school, the most significant relationship is the students' evaluation of the interactions at the center $(\mathrm{RC})\left(.730^{* * *}\right)$ followed by the students' evaluation of their families' relationship with the center $(\mathrm{RF})\left(.643^{* * *}\right)$.

Precisely, the influence of these exclusionary beliefs on becoming a victim, bystander or aggressor of sexual violence at the school is very relevant, with a high level of significance in all cases $(\mathrm{p}<.001)$, and a very high and positive value of the standardized coefficients $(.390 * * *$, $.450 * * *$ and $.505^{* * *}$, respectively). The results indicate that there is a very close relationship between the beliefs that associate love and violence with victimization in terms of sexual violence, being a bystander to these actions and especially, becoming an aggressor (Figure 2).

To evaluate the goodness of fit of our model, we used the indicators recommended by the literature on SEM analysis for large samples (Schlermelleh-Engel et al., 2003, Vandenberg 2006, Byrne, 2010). The indicators of RMSEA (.04), CFI (.98), TLI (.97), NFI (.97) and GFI (.98) show that the matrix derived from the data, and the indicators from the conceptual model do not have significant differences, which indicates that the proposed model can be considered to be very optimal.

\section{[Insert Figure 2 here]}

To test if there were differences by sex in the relationships among the variables, the model was replicated by considering only the subsample of girls $(n=2,022$; see Figure 2 in red) and boys ( $\mathrm{n}=2,038$; see Figure 2 in blue); both models are very optimal (see the indicators of GFI, CFI, TLI, NFI and RMSEA in Figure2).

Although the same pattern of relationships observed for the total sample is followed in both cases, there are some significant differences. In the case of girls, the relationships of the students with their school environment and their families is more relevant in all cases with respect to the total sample and especially if we compare girls results to the subsample of boys. This positive influence of relationships in the prevention of situations of sexual violence is 
especially relevant to the girls in the case of becoming a victim, with a coefficient that is double the boys' coefficient in the same relationship $\left(-.108^{* * *}\right)$. These interactions are also more relevant than the interactions of the total sample or the subsample of boys in terms of not acquiring beliefs that associate love with violence in the case of the girls $\left(-.127^{* * *}\right)$.

If we examine the results of the model with the subsample of men, we can see, as mentioned above, a lesser influence of positive relationships in the participation in violence with a sexual component at school $\left(-.056^{*}\right.$ in the case of victims and $-.050 *$ in the case of bystanders, although it is more important in the aggressors at $-.077 * *)$ and in the acquisition of exclusionary beliefs $\left(-.083^{* *}\right)$, although these relationships remain significant. However, in a relevant way, the fundamental influence of the beliefs that associate love and violence with sexual violence is greater in terms of being an aggressor $(.523 * * *)$.

\section{Discussion and Conclusions}

The importance of socialization in the assumption of different beliefs among adolescents about how they should manage their relationships has been explored in the scientific literature, especially in qualitative research (Racionero et al., 2018; Elboj et al., 2009; Rios-González et al., 2018; Gómez et al., 2014). In the present study, we attempted to apply what these studies have already proposed in relation to the significance of adolescents' interactions and beliefs to prevent sexual violence among this population. We applied these proposals to the design of a structural model, by therefore using a quantitative analysis to explore these issues with a sufficiently representative sample ( $n=4,060$ secondary school students); this is a model that so far has not been tested in the scientific literature.

In this way, by considering the total sample of both boys and girls, it is observed that, as specified Valls et al. (2008), Elboj et al. (2009) and Gómez (2015), socialization achieves great importance in shaping the beliefs of adolescents regarding gender relations. Thus, the influence of the relationships between adolescents and their immediate environment on having beliefs 
associated with gender violence ("The man who seems aggressive is more attractive" and "It is justified that a man attacks his wife or his girlfriend when she decides to leave him") was significant and negative, that is, better relationships are less likely to assume such exclusionary beliefs, as specified by Lindberg et al. (2007), Goldstein et al. (2007) and Puigvert et al. (2019). The relationships that, as observed variables, most contributed to the latent variable of relationships were, as might be hypothesized, the relationships at the school, which has already been emphasized by authors such as Fernández-Fuertes et al. (2006) and Ortega, et al. (2008), and the family relationships with the educational center, as emphasized by Rios-González et al. (2018); these relationships were fundamental variables in these beliefs.

These relationships also have a direct and negative influence on becoming a bystander of episodes of sexual violence, in particular, of being a victim or aggressor of this type of bullying, although it is less than the influence exercised in the assumption of related beliefs with gender relations. This idea of school connectedness as a protective factor has already been indicated in studies related to violence in general at educational centers, such as in the works of CortésPascual et al. (2019), Foster et al. (2017) and Hong et al. (2014), and in terms of being an agent involved in episodes of sexual violence, such as in the studies of Racionero et al. (2018), Valls et al., (2008), Elboj et al. (2009), De La Rue (2014) and Shakya, et al. (2019).

However, also aligned with previous literature, there is a direct and very relevant influence of the beliefs related to gender violence and being a victim, bystander or aggressor of sexual violence, especially of being an aggressor, since having these beliefs increase becoming an aggressor of sexual violence by more than $50 \%$. These results confirm previous theories in which the importance of ideas about relationships as a fundamental element to understand the causality of sexual and/or gender violence is emphasized (L'Engle, et al., 2006; Gómez, 2015; Valls et al., 2008; Racionero et al., 2018). 
In the comparison between the subsamples, in all the variables of sexual violence, the percentage of men is more relevant than the percentage of girls both in victimization, as already warned by Messerschmidt (2017), and in observation and aggression, which has been observed in previous research carried out in Spain (Ortega et al. 2008, Díaz-Aguado et al., 2013). In the case of beliefs, and again confirming previous research (Elboj et al., 2009; Gómez, 2015; RiosGonzález et al., 2018), considering an aggressive man as more attractive and its relationship with sexual violence is indistinctly evident in boys and girls. Observing the two structural models that refer to girls, on the one hand, and boys, on the other hand, it is evident that in both cases, the pattern evidenced in the general model is followed. However, the connection to their environment can be very relevant to girls, especially in preventing them from becoming victims, since such interactions can foster transformative beliefs that protect against this victimization, which endorses the research by Racionero et al. (2018). In fact, having these exclusionary beliefs (especially associating attraction with aggressiveness in boys) increases the possibility of becoming a victim by $36.8 \%$. In the case of the boys, although interactions are less relevant to the assumption of beliefs and as a protective factor of sexual violence, these interactions remain significant, and it is very necessary to work on the concepts of masculinity associated with these beliefs (Rios-González et al., 2018), especially when it is observed that exclusionary beliefs increase the possibility of becoming a sexual violence aggressor by $52.3 \%$.

Accordingly, if socialization has a relevant influence on the beliefs about love and violence that are transmitted and both of these factors have an influence on the participation in situations of sexual violence, preventive socialization emerges as a fundamental strategy to combat sexual violence among adolescents. Following Foster et al. (2017) and Rios-Gonzalez, et al. (2019), at school, healthy, supportive relationships for well-being throughout life should be promoted, with special emphasis and reflection on personal relationships based on respect and nonviolence. This network of support and prevention must consider not only all the 
socialization agents of the school (peers, teachers, managers, and other school staff) but also, in a very relevant way, the families and their participation at the educational center. To turn schools into safe and violence-free spaces and to increase the social impact (Flecha, et al., 2015) on the prevention of sexual violence in secondary education, these types of relationships and interactions between the different groups involved in schools should be promoted.

Regarding the limitations of this study, the variables used could not cover the entire spectrum of possible beliefs associated with gender violence and sexual violence behaviors, and subjective interpretations of own relationships can limit the results, although the variables used can be justified by the fact that the validated questionnaire of Díaz Aguado et al. was used (2013), which includes only these variables and has been the most frequently used in the Spanish context. As diversity of participants was considered (private and public schools, both sexes, migrant background and natives etc.) generalizability of the findings can be claimed. However, the sample could be considered to be slightly biased, given that it was carried out in a specific region (Aragón, Spain), although the results are aligned with numerous previous works on the topic. Another of the limitations of the study is its exploratory nature, based on previous qualitative studies, proposing a quantitative model not previously developed in the scientific literature. Finally, regarding future lines of research, we consider that the dynamics of the prevention of gender violence need further study by considering other variables and agents that may influence them.

\section{References}

Aiello, E., Puigvert, L., \& Schubert, T. (2018). Preventing violent radicalization of youth through dialogic evidence-based policies. International Sociology, 33(4), 435-453. doi: $10.1177 / 0268580918775882$.

Bakhtin, M. M. (1981). The dialogic imagination. University of Texas Press.

Byrne, B. (2010). Structural Equation Modeling with AMOS. London: Routledge. 
Cortés-Pascual; A., Cano-Escoriaza, J., Elboj-Saso, C., Iñiguez-Berrozpe, T. (2019). Positive relationships for the prevention of bullying and cyberbullying: A study in Aragón (Spain). International Journal of Adolescence and Youth. doi:

$$
10.1080 / 02673843.2019 .1602064
$$

Díaz-Aguado, M.J., Martínez-Arias, R. y Martín Bábarro, J. (2011). Estudio estatal sobre la convivencia escolar en la educación secundaria obligatoria. Ministerio de Educación. Observatorio Convivencia Escolar.

Díaz-Aguado, M.J., Martínez-Arias, R. \& Babarro, J. (2013). El acoso entre adolescentes en España. Prevalencia, papeles adoptados por todo el grupo y características a las que atribuyen la victimización. Revista de Educación, 362, pp. 348-379

Eisman, A. B., Ngo, Q. M., Kusunoki, Y. Y., Bonar, E. E., Zimmerman, M. A., Cunningham, R. M., \& Walton, M. A. (2018). Sexual violence victimization among youth presenting to an urban emergency department: The role of violence exposure in predicting risk. Health Education \& Behavior, 45(4), 625.

Elboj, C., Iñiguez, T., Flecha, A. (2009). Modelos de atracción y elección de la población adolescente y su relación con la violencia de género. Propuesta para su prevención en base a los principios pedagógicos de las Comunidades de Aprendizaje. Contextos Educativos, 12, pp. 95

Fernández-Fuertes, A. A., Fuertes, A. y Pulido, R. R. (2006). Evaluación de la violencia en las relaciones de pareja de los adolescentes. Validación del Conflict in Adolescent Dating Relationships Inventory (CADRI) - versión española. Internacional Journal of Clinical Health Psycology, 6(2), 339-358

Fernet, M., Hébert, M., Couture, S., \& Brodeur, G. (2019). Meeting the needs of adolescent and emerging adult victims of sexual violence in their romantic relationships: A mixed methods study exploring barriers to help-seeking. Child Abuse \& Neglect, 91, 41-51. 
Flecha, R., Oliver, E., Puigvert, L., and Soler, M. (2017). Analitical Categories that Result from the Research Line on Preventive Socialization of Gender Violence Developed by CREA.

Flecha, R., Soler, M., and Sordé, T. (2015). Europe must fund social sciences. Nature 520, 193-193. doi: 10.1038/528193d

Foshee, V., McNaughton Reyes, H., Chen, M., Ennett, S., Basile, K., DeGue, S., ... Bowling, J. (2016). Shared Risk Factors for the Perpetration of Physical Dating Violence, Bullying, and Sexual Harassment Among Adolescents Exposed to Domestic Violence. Journal of Youth \& Adolescence, 45(4), 672-686

Goldstein, S. E., Malanchuk, O., Davis-Kean, P., \& Eccles, J. S. (2007). Risk factors of sexual harassment by peers: A longitudinal investigation of african american and european american adolescents. Journal of Research on Adolescence, 17(2), 285-300.

Gómez, J. (2015). Radical Love. A Revolution for the $21^{\text {st }}$ century. New York: Peter Lang Publishing.

Harris, S., \& Petrie, G. F. (2003). Bullying: The bullies, the victims, the bystanders. Lanham, MD: Scarecrow Press.

Hong, J.H., Lee, C.H, Lee, J., Lee N.Y \& Garbarino, J. (2014). A Review of Bullying Prevention and Intervention in South Korean Schools: An Application of the SocialEcological Framework. Child Psychiatry and Human Development, 45, 4, 433-442. doi: 10.1007/s10578-013-0413-7

Instituto Nacional de Estadística (2019). Menores condenados por delitos sexuales en España. Retrieved from http://www.ine.es/dynt3/inebase/index.htm?padre=3977\&capsel=4021 Joanpere, M. \& Morlà, T. (2019). Nuevas Masculinidades Alternativas, la lucha con y por el feminismo en el contexto universitario. Masculinities and Social Change, 8(1),42-63. doi: $10.17583 / \mathrm{mcs} .2019 .3936$. 
Jouriles, E. N., McDonald, R., Rosenfield, D., \& Sargent, K. S. (2019). Increasing Bystander Behavior to Prevent Adolescent Relationship Violence: A Randomized Controlled Trial. Journal of Consulting \& Clinical Psychology, 87(1), 3.

Kaltiala-Heino, R., Savioja, H., Fröjd, S., \& Marttunen, M. (2018). Experiences of sexual harassment are associated with the sexual behavior of 14- to 18-year-old adolescents. Child Abuse and Neglect, 77, 46.

Keith, T. Z. (2006). Multiple Regression and Beyond. Toronto: Pearson Education

L'Engle, K. L., \& Jackson, C. (2008). Socialization influences on early adolescents' cognitive susceptibility and transition to sexual intercourse. Journal of Research on Adolescence, $18(2), 353-378$.

Lloyd, C. B., Grant, M., \& Ritchie, A. (2008). Is being popular a risky proposition? Journal of Research on Adolescence, 18(1), 49-74.

Mahlstedt, D. L., \& Welsh, L. A. (2005). Perceived causes of physical assault in heterosexual dating relationships. Violence Against Women, 11, 447-472.

Messerschmidt, J. W. (2017). Adolescent Boys, Embodied Heteromasculinities and Sexual Violence. Center for Educational Policy Studies Journal, 7(2), 113-126.

Mead, G. H. (1934). Mind, self and society from the standpoint of a social behaviorist. Chicago: University of Chicago Press.

Miller, E. (2019). Reclaiming Gender and Power in Sexual Violence Prevention in Adolescence. Violence Against Women, 24(15), 1785-1793

Ngo, Q. M., Veliz, P. T., Kusunoki, Y., Stein, S. F., \& Boyd, C. J. (2018). Adolescent sexual violence: Prevalence, adolescent risks, and violence characteristics. Preventive Medicine, 116, 68-74 
Ortega, R., Ortega-Rivera, J. y Sánchez V. (2008). Violencia Sexual entre compañeros/as y violencia en parejas adolescentes. International Journal of Psychology and Psychological Therapy, 8(1), 63-72.

Puigvert, L., Gelsthorpe, L., Soler-Gallart, M. \& Flecha, R. (2019). Girls’ perceptions of boys with violent attitudes and behaviours, and of sexual attraction. Palgrave Communications, 5(56), doi: 10.1057/s41599-019-0262-5.

Racionero, S., Ugalde, L., Puigvert, L. \& Aiello, E. (2018). Reconstruction of Autobiographical Memories of Violent Sexual-Affective Relationships Through Scientific Reading on Love: A Psycho-Educational Intervention to Prevent Gender Violence. Frontiers in Psychology, 9. doi: 10.3389/fpsyg.2018.01996

Rawlings, J. (2015). The Effect of Middle School Music Ensemble Participation on the Relationship between Perceived School Connectedness, Self-Reported Bullying Behaviors, and Peer Victimization. Bulletin of the Council for Research in Music Education, 213, 53-72. doi:10.5406/bulcouresmusedu.213.0053

Redondo, G.; Pulido-Rodríguez, M.; Larena, R.; \& de Botton, L. (2014). No Without Them: The Inclusion of Minors' Voices on Cyber Harassment Prevention. Qualitative Inquiry, 20(7), 895-901. doi: 10.1177/1077800414537214

Rios-González O., Peña Axt J.C., Duque Sánchez E., \& De Botton Fernández, L. (2018) The Language of Ethics and Double Standards in the Affective and Sexual Socialization of Youth. Communicative Acts in the Family Environment as Protective or Risk Factors of Intimate Partner Violence. Frontiers in Sociology, 3(19). doi:

10.3389/fsoc. 2018.00019

San Segundo, R., \& Codina-Canet, A. (2019). Enunciación de la Violencia de Género y Marco Educativo para su Prevención. Multidisciplinary Journal of Gender Studies, 8(1), 26-47. doi: 10.17583/generos.2019.4000 
Santoyo Castillo, D \& Frías, S. (2014). Acoso escolar en México: actores involucrados y sus características. Revista Latinoamericana de Estudios Educativos, 154, 4, 2014, 13-41.

Shakya, H. B., Fariss, C. J., Ojeda, C., Raj, A., \& Reed, E. (2019). Social Network Clustering of Sexual Violence Experienced by Adolescent Girls. American Journal of Epidemiology, 186(7), 796-804. doi: 9443/10.1093/aje/kwx15

Shin, Y. (2000). A comparison study in bullying of middle school students: Focus on social environment. Seoul, South Korea: Joongang University

Storer, H. L., Casey, E. A., \& Herrenkohl, T. I. (2017). Developing “whole school” bystander interventions: The role of school-settings in influencing adolescents responses to dating violence and bullying. Children and Youth Services Review, 74, 87-95

Valls, R., Puigvert, L., \& Duque, E. (2008). Gender violence among teenagers. Socialization and prevention. Violence Against Women, 7, 759-785.

Vandenberg, R. J. (2006). Statistical and Methodological Myths and Urban Legend. Organizational Research Methods, 9(2), 194-201

Villarejo-Carballido, B., Pulido, C.M., de Botton, L., Serradell, O. (2019). Dialogic Model of Prevention and Resolution of Conflicts: Evidence of the Success of Cyberbullying Prevention in a Primary School in Catalonia. International Journal of Environmental Research and Public Health, 16, 918. doi: 10.3390/ijerph16060918

WHO (2012). Understanding and addressing violence against women. Retrieved from https://apps.who.int/iris/bitstream/handle/10665/77434/WHO_RHR_12.37 eng.pdf?seq $\underline{\text { uence }}=1$

Yang, J. (2005). A study on causal factors of bullying among middle school students. Journal of Korean Education, 32(2), 31-52

Footnotes

${ }^{1}$ In Spain public schools are financed by the state, being the responsibility of the country's Ministry of Education and Science, although he
17 autonomous communities are responsible for their own education system. On the other hand, private schools can be parochial 
schools, bilingual schools, international schools and a variety of foreign schools, and their budget depends on students' family's monthly fees. In Spain almost one third of children attend private schools

${ }^{2}$ Regarding the directionality of the relationships, the proposal by Keith $(2006$, p.249) was considered, who specifies that although the directionality in the regressions may be problematic of justification, "theory, previous research and logic are the appropriate tools for making such judgments"; therefore, we assumed the dependence of the beliefs regarding interactions and the participation in sexual aggressions as dependent on the "beliefs" or "interactions", as established in the literature.

${ }^{3}$ The limit criteria for the goodness of fit recommended by Schlermelleh-Engel et al. (2003), Vandenberg (2006) and Byrne (2010) and followed in this paper are RMSEA $<.80, \mathrm{CFI}>.93$, TLI $>.90, \mathrm{NFI}>.90$, and GFI $>.90$ 


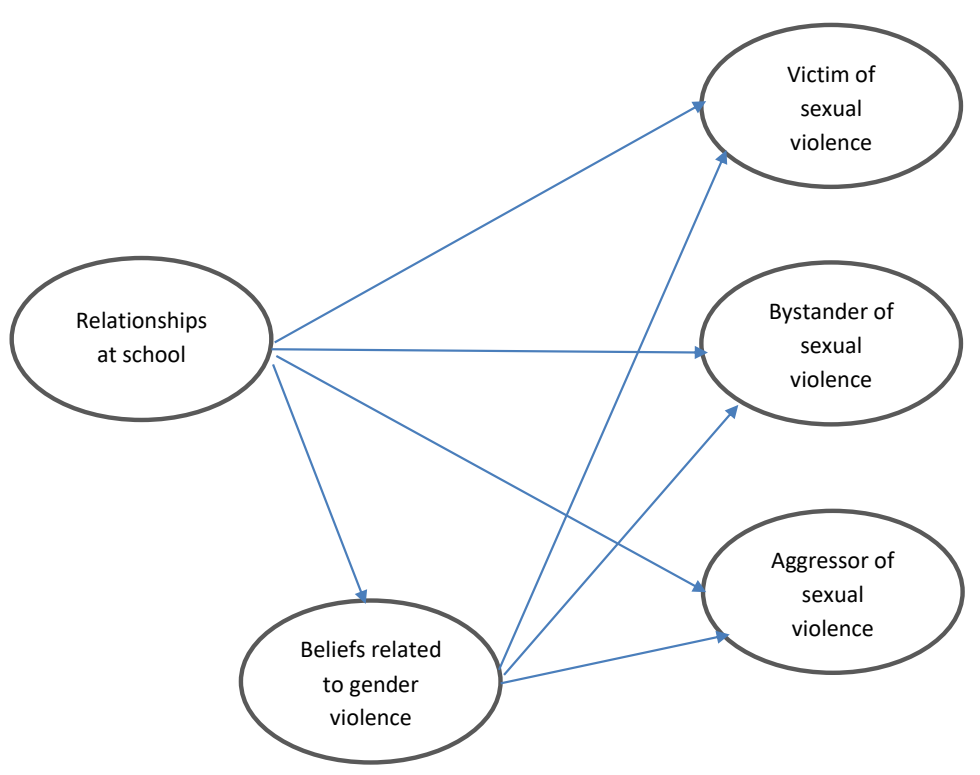

Figure 1. Hypothetical model: Influence of relationships at school between adolescents and their environment and the assumed beliefs on gender violence to sexual violence 


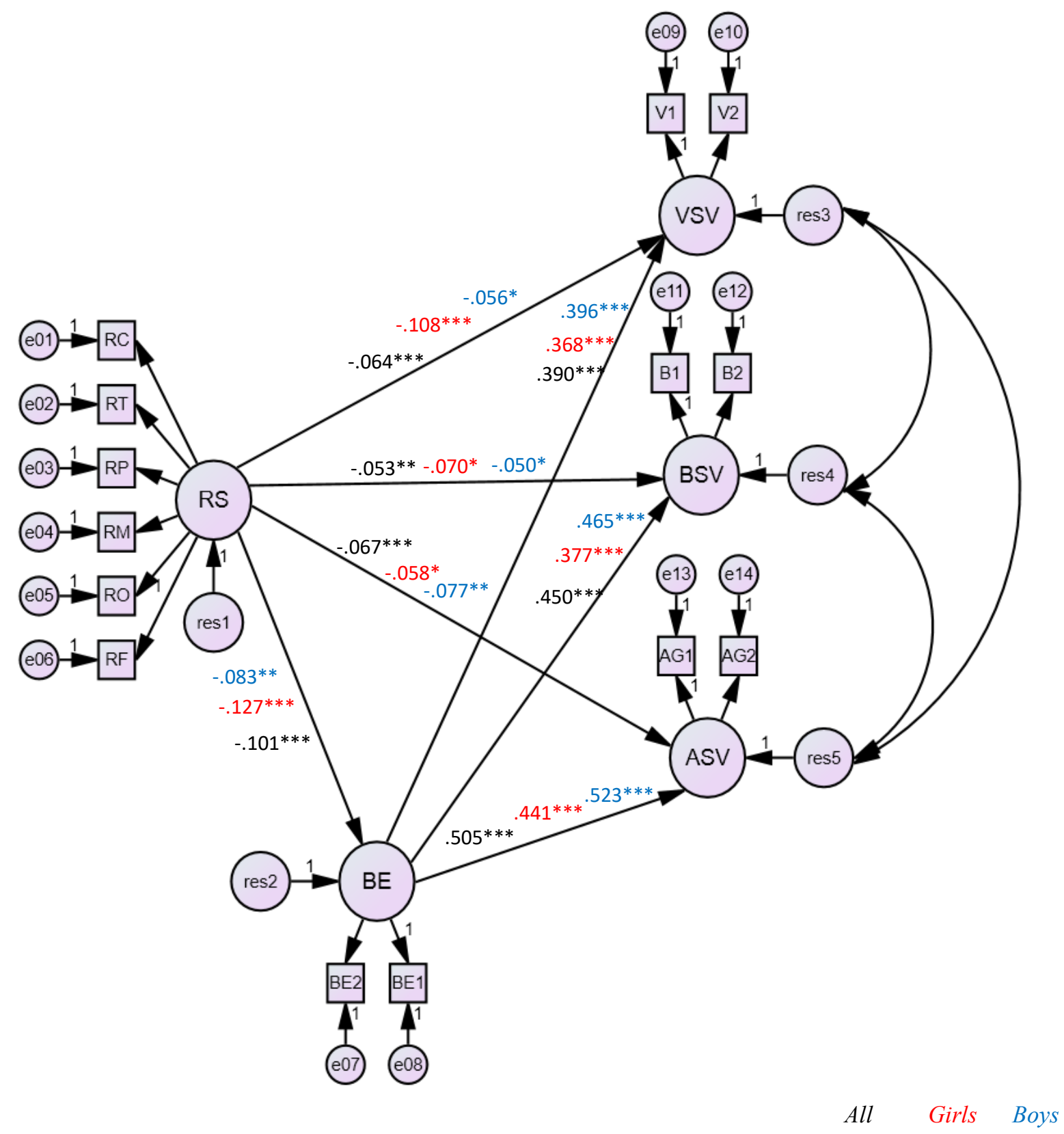

Figure 2. Visual representation of the models (all; girls; boys) on AMOS. With standardized coefficients and significance levels of $* \mathrm{p}<.05 * * \mathrm{p}<.01 * * * \mathrm{p}<.001$.

Model (all): $\mathrm{GFI}=.98 ; \mathrm{CFI}=.98 ; \mathrm{TLI}=.97 ; \mathrm{NFI}=.97 ; \mathrm{RMSEA}=.04 ; \mathrm{N}=4,060$

Model (girls): $\mathrm{GFI}=.97 ; \mathrm{CFI}=.96 ; \mathrm{TLI}=.94 ; \mathrm{NFI}=.95 ; \mathrm{RMSEA}=.05 ; \mathrm{n} .=2,022$

Model (boys): $\mathrm{GFI}=.98 ; \mathrm{CFI}=.98 ; \mathrm{TLI}=.97 ; \mathrm{NFI}=.98 ; \mathrm{RMSEA}=.04 ; \mathrm{n} .=2,038$

RS: Relationships at school; RC: Relationships: at this center; RT: Relationships: with teachers; RP: Relationships: with your peers in class; RM: Relationships: with school managers; RO: Relationships: with custodians and other school staff; RF: Relationships: between your family and the school

BE: Beliefs related to gender violence; BE1: Men who look aggressive are more attractive; BE2: It is justified that a man attacks his wife or his girlfriend when she decides to leave him

VSV: Victim sexual violence; V1: They intimidate me with phrases or insults of a sexual nature; V2:

They force me with threats of behaviors or situations of a sexual nature in which I do not want to participate

BSV: Bystander sexual violence; B1: (witnessed) Intimidating him/her with phrases or insults of a sexual nature; B2: (witnessed) Forcing him/her with threats of behaviors or situations of a sexual nature in which he/she doesn't want to participate

ASV: Aggressor sexual violence: AG1: (participated) Intimidating him/her with phrases or insults of a sexual nature; AG2: (participated) Forcing him/her with threats of behaviors or situations of a sexual nature in which he/she doesn't want to participate 
Table 1. Sociodemographic features of the sample

\begin{tabular}{|c|c|c|}
\hline & & $\% /$ Mean $(\mathrm{SD})$ \\
\hline \multirow[t]{2}{*}{ Sex } & Female & 49.8 \\
\hline & Male & 50.2 \\
\hline Age & & $14.2(1.4)$ \\
\hline \multirow[t]{4}{*}{ Course } & $1^{\text {st }}$ & 23.7 \\
\hline & $2^{\text {nd }}$ & 26.6 \\
\hline & $3^{\text {rd }}$ & 24.9 \\
\hline & $4^{\text {th }}$ & 22.0 \\
\hline \multirow[t]{2}{*}{ Country of birth } & Spain & 91.0 \\
\hline & Other country & 9.0 \\
\hline \multirow[t]{2}{*}{ Father's country of birth } & Spain & 87.7 \\
\hline & Other country & 12.3 \\
\hline \multirow[t]{2}{*}{ Mother's country of birth } & Spain & 87.0 \\
\hline & Other country & 13.0 \\
\hline \multirow[t]{5}{*}{ Father's educational level } & None & 3.6 \\
\hline & ISCED 1 & 14.3 \\
\hline & ISCED 2-4 & 35.3 \\
\hline & ISCED 5 & 14.8 \\
\hline & ISCED 6-7 & 32.0 \\
\hline \multirow[t]{5}{*}{ Mother's educational level } & None & 2.9 \\
\hline & ISCED 1 & 12.2 \\
\hline & ISCED 2-4 & 32.6 \\
\hline & ISCED 5 & 15.9 \\
\hline & ISCED 6-7 & 36.3 \\
\hline \multirow[t]{3}{*}{ Repeated a course in secondary education } & No, never & 81.8 \\
\hline & Yes, once & 13.3 \\
\hline & Yes, twice or more & 1.5 \\
\hline \multirow[t]{3}{*}{ Repeated a course in primary education } & No, never & 90.2 \\
\hline & Yes, once & 9.3 \\
\hline & Yes, twice or more & 0.4 \\
\hline
\end{tabular}

$\mathrm{n}=4,060$ 
Table 2. Variables used in the model

\begin{tabular}{|c|c|c|c|}
\hline Latent variables & & Observed variables & \\
\hline Description & Label & Description & Label \\
\hline \multirow[t]{6}{*}{ Relationships at school } & \multirow[t]{6}{*}{ RS } & Relationships: at this center & $\mathrm{RC}$ \\
\hline & & Relationships: with teachers & RT \\
\hline & & Relationships: with school managers & $\mathrm{RM}$ \\
\hline & & Relationships: with custodians and other school staff & RO \\
\hline & & Relationships: between your family and the school & $\mathrm{RF}$ \\
\hline & & Relationships: with your peers in class & $\mathrm{RP}$ \\
\hline \multirow{2}{*}{$\begin{array}{l}\text { Beliefs related to gender } \\
\text { violence }\end{array}$} & \multirow[t]{2}{*}{$\mathrm{BE}$} & Men who look aggressive are more attractive & BE1 \\
\hline & & $\begin{array}{l}\text { It is justified that a man attacks his wife or his girlfriend when she } \\
\text { decides to leave him }\end{array}$ & BE2 \\
\hline \multirow[t]{2}{*}{ Victim sexual violence } & \multirow[t]{2}{*}{ VSV } & They intimidate me with phrases or insults of a sexual nature & V1 \\
\hline & & $\begin{array}{l}\text { They force me with threats of behaviors or situations of a sexual } \\
\text { nature in which I do not want to participate }\end{array}$ & $\mathrm{V} 2$ \\
\hline \multirow[t]{2}{*}{ Bystander sexual violence } & \multirow[t]{2}{*}{ BSV } & Intimidating him/her with phrases or insults of a sexual nature* & B1 \\
\hline & & $\begin{array}{l}\text { Forcing him/her with threats of behaviors or situations of a sexual } \\
\text { nature in which he/she doesn't want to participate* }\end{array}$ & B2 \\
\hline \multirow[t]{2}{*}{ Aggressor sexual violence } & \multirow[t]{2}{*}{ ASV } & Intimidating him/her with phrases or insults of a sexual nature** & AG1 \\
\hline & & $\begin{array}{l}\text { Forcing him/her with threats of behaviors or situations of a sexual } \\
\text { nature in which he/she doesn't want to participate** }\end{array}$ & AG2 \\
\hline
\end{tabular}


Table 3. Descriptive analysis of the variables used in the model. Percentage and level of significance

\begin{tabular}{lcr}
\hline & Women & Men \\
\hline & $\%$ of incidence & $6.5^{* * *}$ \\
\hline V1. They intimidate me with phrases or insults of a sexual nature & $3.9^{* * *}$ & $1.5^{* * * *}$ \\
V2. They force me with threats of behaviors or situations of a sexual & & $13.9^{* * *}$ \\
nature in which I do not want to participate & $9.5^{* * *}$ & $9.3^{* * *}$ \\
B1. Intimidating him/her with phrases or insults of a sexual nature & $4.1^{* * *}$ & $6.8^{* * *}$ \\
B2. Forcing him/her with threats of behaviors or situations of a sexual & $2.5^{* * *}$ & $6.3^{* * *}$ \\
nature in which he/she doesn't want to participate & $1.9^{* * *}$ & \\
AG1. Intimidating him/her with phrases or insults of a sexual nature & & \\
AG2. Forcing him/her with threats of behaviors or situations of a & & \\
sexual nature in which he/she doesn't want to participate &
\end{tabular}
sexual nature in which he/she doesn't want to participate

$\%$ of students that agree with the statement

BE1. Men who look aggressive are more attractive

BE2. It is justified that a man attacks his wife or his girlfriend when

$2.3^{* * *}$

$4.7 * * *$ she decides to leave him

$\%$ of students satisfied or very satisfied with the relationship

RC. Relationships: at this center

88.1

RT. Relationships: with teachers

RM. Relationships: with school managers

RO. Relationships: with custodians and other school staff

RF. Relationships: between your family and the school

$91.0 * *$

RP. Relationships: with your peers in class

$* \mathrm{p}<.05 ; * * \mathrm{p}<.01 ; * * * \mathrm{p}<.001$ 